\title{
Reading Strategies on EFL Students of English Education Study Program
}

\author{
Dyah Kurniawati \\ University of PGRI Ronggolawe
}

\author{
Karina Eka Puspita \\ University of PGRI Ronggolawe
}

\begin{abstract}
This article is intended to describe the reading strategies use and also the differences between male and female on using reading strategies by EFL students English Educational Study Program at the 8thSemester of Ronggolawe University. This article employed mixed methods combining quantitative and qualitative method. The researcher takes 40 students of class 2013 A and B at English Department of Unirow Tuban as subjects of the research and they were categorized into two groups of participants namely: male and female students. The purpose of this article was to explore the use of English as a Foreign Language (EFL) reading strategies used by English department students. The Survey of Reading Strategies (SORS) by Mokhtari and Reichard was used as the instrument to collect data on the participants' usage of reading strategies. The questionnaires were analyzed using Likert scale from 1 to 5 , and the interviews were descriptively. All of instruments are used to know reading strategies used by EFL students. The results revealed that students used EFL reading strategies frequently. Of the three strategy sub-categories, problem-solving reading strategies were used by students the most, followed by support reading strategies and then global reading strategies. Male students showed greater awareness of EFL reading strategies than female students in all three subcategories, as well as in the 30 individual reading strategies. It also found that male students used EFL reading strategies significantly more frequently than female students.
\end{abstract}

Keywords-EFL students, strategies, reading strategies

\section{INTRODUCTION}

Language is a form of communication. Therefore mastering of English is something which is very essential for everybody who wants to increase his or her knowledge and technology. English is an international language, almost people from all over the world use English for their communication that is why English is very important language. People use the language to express their emotions, feelings, and ideas. No one will be able to communicate internationally without using English since almost all of scientific book are written in English. For that reason in Indonesia, English is the foreign language taught at the formal schools. Furthermore, the teaching of the language starts from the kindergarten.

English as a subject matter in school that contains of the four basic language skills: reading, speaking, writing and listening. In every subject, students learning activities involve reading. Reading is one of the complex ways in learning English.

Reading in a second or foreign language (SL/FL) has been a significant component of language learning over the past forty years [1]. This significance has made reading education an important issue in educational policy and practice for English language learners [2]. However, reading is a complex, interactive cognitive process of extracting meaning from text. In the reading process, the reader is an active participant, constructing meaning from clues in the reading text. Reading is also an individual process, which explains the different interpretations of different readers [3]. Reference [4] reported that simple methods such as underlining, taking notes, or highlighting the text can help readers understand and remember the content. Their findings indicated that in reading text, good readers often use effective reading strategies to enhance their comprehension. According to the above, learning to read is an absolutely necessary skill for understanding SL/FL texts. Readers may use useful strategies to help them read SL/FL texts as they construct meaning. Using such strategies will help learners not only to understand general information in the reading text at very fast rates but also to remember new lexical items from the text.

So many attempts have been made to develop and make students aware of reading strategies that they use while studying. Meta-cognitive awareness is the awareness of whether or not comprehension is occurring and the conscious application of one or more strategies to overcome comprehension failures. Reference [5] developed Survey of Reading Strategies (SORS) based on the MetacognitiveAwareness-of-Reading-Strategies Inventory (MARSI) to identify the perceived use of the type of frequency of strategies by students while reading materials in English. SORS categorizes reading strategies used by learners into three categories of global, problem-solving, and support. Global strategies are those strategies learners use to monitor their progress, plan for reading, and set reading strategies. They include 13 strategies as: setting purpose for reading, using prior knowledge, previewing text before reading, checking how text content fits purpose, noting text characteristics, determining what to read, resolving conflicting information, confirming predictions, using context clues, using text features, predicting or guessing text meaning, evaluating what is read critically, and using typographical aids (e.g. italics). 
Despite these studies about awareness of reading strategies, there have been few studies on the use of reading strategies of students Ronggolawe University. So this study tries to identify The Use of Reading Strategies of EFL Students English Education Study Program at the $8^{\text {th }}$ Semester of Ronggolawe University. In order to meet this goal, Survey of Reading Strategies (SORS) developed by ref [5] based on the Metacognitive-Awareness-of-ReadingStrategies Inventory (MARSI) is used.

\section{LITERATURE REVIEW}

\section{A. The Importance of Reading Strategies}

In educational system, most of EFL learners face many problems especially in comprehension of written materials when reading. According to them, understanding the meaning of texts can be a great challenge i.e. they able to understand each word and even each sentence; but unfortunately, they fail to achieve the meaning of text as a whole. For that reason, many psychologies and researchers assume that those who always struggle and find reading comprehension as a problematic issue. Because of most of these students lack the reading strategies that may help them to overcome their reading problems.

There are much evidence that have been shown on the importance of reading strategies and their effective role in enhancing and developing reading comprehension. Reference [6] views that "reading strategies are more useful and beneficial for learners who show lack of knowledge in the domain of reading, as well as those with lower reading skill, these kinds of learners are strongly needed to these strategies to achieve reading comprehension". Therefore, the continuous use of reading strategies will lead the readers to become skilled and later they will be able to utilize the reading skills acquired without conscious efforts.

\section{B. Classification of Reading Strategies}

Reference [7] suggested a reading strategy questionnaire called MARSI (Metacognitive Awareness of Reading Strategies Inventory) to measure learners strategy use while reading academic materials. They divided reading strategies into three subgroups: global strategies (orienting towards global analysis of the texts), problem-solving strategies (aiming at solving problems when the text becomes difficult), and support strategies (using reference materials, note-taking and other practical strategies). Based on MARSI's factor analyses and theoretical framework, MARSI was adjusted into a new version of survey called SORS (Survey of Reading Strategies) with three categories of reading strategies: metacognitive strategies, cognitive strategies and support strategies. This is one of the very few comprehensive taxonomies of reading strategies with clear descriptions of each category, thus will be selected as the classification framework in this paper.

Metacognitive reading strategies as purposeful, carefully planned action employed by readers to monitor or manage their reading (for example, setting goals before reading, skimming the text to preview its length and structure, etc.). Metacognitive strategies as executive actions that involve planning, monitoring or evaluating one ${ }^{\text {ee }}$ s learning process. Metacognitive strategies entail three major tasks: centering one's learning, arranging and planning one's learning, and evaluating one's learning. Although these definitions are not entirely the same, all the authors agreed that metacognitive strategies involve some elements of planning and monitoring one's study.

Cognitive reading strategies are defined as the localized techniques utilized by readers while working directly with the text, especially when it becomes difficult. Some typical examples are changing reading speed, inferring from context, re-reading for better comprehension, etc. This definition is very similar to the concept of problem-solving strategies suggested by ref [7], as previously mentioned. Cognitive strategies 'operate directly on incoming information, manipulating it in ways that enhance learning'. That is to say, one typical characteristic of this group of strategies is to deal directly with the problems arising while reading.

Support strategies refer to the use of basic support mechanisms to aid comprehension. This category had not been mentioned in any previous taxonomy of language learning strategies. It was coined by ref [7] in MARSI. Both researches conceptualized support strategies as applying support mechanisms like using dictionaries, taking notes, summarizing, underlining key words, etc. to improve reading comprehension.

A clear classification of reading strategies is really beneficial, especially when this research sought to measure the effects of different subgroups of strategies on reading comprehension. However, it should be noted that sometimes the distinctions between two categories are not very clearcut. This means that a specific strategy may reflect the characteristics of more than one category, and does not entirely belong to any particular group. Such ambiguity is inevitable in many literature-based taxonomies, thus should be taken into account in the step of analyzing data for this research.

\section{METHOD}

This research employed mixed methods combining quantitative and qualitative approaches to allow for greater accuracy. In particular, quantitative data was collected through a self-report Reading Strategy Questionnaire based on by ref [7], accompanied by Survey Of Reading Strategies (SORS). Meanwhile, qualitative data was gathered via semi structured interviews with my self-designed questions. Although quantitative analysis is still the centre of this study, some qualitative analysis should be conducted to support the quantitative evidence and triangulate the pool of research data. Descriptive study is chose due to the type of the study which is to know the learning strategies of EFL students English education study program. 


\section{FINDING AND DISCUSSION}

The questionnaires were administrated to 40 students of English Education Department that comes from class 2013 $\mathrm{A}$ and $2013 \mathrm{~B}$, the $8^{\text {th }}$ semester students. There are 10 students who are the male, and 30 students who are the female. The total both of them are 40 students.

The questionnaire consisted of the 30 individual reading strategies (global, problem-solving and support strategies) are presented in the order of use frequency, from high (3.5 and above) and moderate (2.5 3.4) to low (2.4 and under).To find the used strategies, they have to complete SORS (Survey of Reading Strategies). There are 5 options in every statement, 1 means never, 2 means seldom, 3 means sometimes, 4 means often, and 5 means always. SORS categorizes reading strategies used by learners into three categories of global, problem-solving, and support.

Global strategies are those strategies learners use to monitor their progress, plan for reading, and set reading strategies. They include 13 strategies as: setting purpose for reading, using prior knowledge, previewing text before reading, checking how text content fits purpose, noting text characteristics, determining what to read, resolving conflicting information, confirming predictions, using context clues, using text features, predicting or guessing text meaning, evaluating what is read critically, and using typographical aids (e.g. italics). Statement number 1, 3, 4, 6, $8,12,15,17,20,21,23,24$, and 27 indicate global reading strategies. Students who get high score on these numbers. It means they mostly use global reading strategies.

Problem-solving strategies aid the reader in constructing meaning from the text. These strategies include 8 items as: guessing meaning of unknown words, trying to stay focused on reading, rereading for better understanding, paying close attention to reading, reading slowly and carefully, pausing and thinking about reading, adjusting reading rate, and visualizing information read. Statement number 7, 9, 11, 14, $16,19,25$, and 28 indicate problem reading strategies. Students who get high score on these numbers, it means they mostly use problem-solving reading strategies.

Support strategies are those means learners employ when text comprehension eludes them even after the use of global and problem-solving strategies. They include 9 items: underlining information in the text, paraphrasing for better understanding, thinking both in English and mother tongue while reading, going back and forth in the text, taking notes while reading, translating into mother tongue, using reference material, asking oneself questions, and reading aloud when text becomes hard. Statement number 2, 5, 10, $13,18,22,26,29$, and 30 indicate support reading strategies. Students who get high score on these numbers, it means they mostly use support reading strategies. Each number of questionnaires was written in Indonesian language to avoid any misinterpretation and to make easier the respondents in completing the questionnaires. After obtaining data from the questionnaire, the data is calculated. The researcher used questionnaire in order to collect the data of the SORS. The result was analyzed using Microsoft
Excel 2007 to get the result of analysis appropriately. In this section, means and standard deviation for the overall learning strategy use in the SORS were presented to show the general picture of learning strategy used by the $8^{\text {th }}$ semester students. Next, means and standard deviation for the three categories and all the strategy items in the SORS were also presented to determine learning strategy used by each group.

\section{A. Reading Strategies of Students}

Results for each of the 30 individual reading strategies (global, problem-solving, and support) are presented in the order of use frequency, from high (3.5 and above) and moderate $(2.5 \sim 3.4)$ to low (2.4 and under), in this table below, the respondents reported 11 high-frequency strategies and 25 moderate-frequency ones, and 4 lowfrequency reading strategies. The most frequently used reading strategy was a problem solving strategy. It was followed by one support strategy, and one global strategy.

Students applied the strategies in reading. Therefore, it can be concluded that they often use all of the strategies. However, there is one strategy they use more often than the other strategies. Since the mean of problem solving reading strategies is more than problem reading strategies and global reading strategies. It means the students mostly applied problem solving reading strategies. It is followed by support reading strategies and global reading strategy. To know the percentage of every strategy the researcher tabulates the result in the following TABLE I.

TABLE I. Reading Strategies

\begin{tabular}{|l|c|c|}
\hline \multicolumn{1}{|c|}{ Reading Strategies } & Students & Percentage \\
\hline Global Reading Strategies (GLOB) & 4 & $10 \%$ \\
\hline $\begin{array}{l}\text { Problem Solving Reading Strategies } \\
\text { (PROB) }\end{array}$ & 23 & $57.5 \%$ \\
\hline Support Reading Strategies (SUP) & 13 & $32.5 \%$ \\
\hline
\end{tabular}

From the table above, there are $10 \%$ of the students use global reading strategies more often, $57.5 \%$ of the students use problem solving reading strategies, and $32.5 \%$ the other students use support reading strategies more often. From the description, it can be concluded that the most dominant strategies are use by the students is problem solving reading strategies. It is followed by support reading strategies and global reading strategies.

\section{B. Reading Strategies of Students Different Gender}

There were significant differences between male and female students. The results also revealed that problemsolving reading strategies were often used by both male $(60 \%)$ and female $(53.33 \%)$ students, but male students used them significantly more often than female students. In the use of global reading strategies, both male (10\%) students and female (16.66\%) students seldom used this strategy. However, female students used them significantly more often than male students. In the use of support reading strategies, male (30\%) and female (30\%) students used reading strategies with the same percentage, it can be 
conclude that male and female students with the balance used this strategy.

After counting the result of the SORS, the researcher concluded that strategies are used by the students. Since there are 30 statements which global reading strategies (GLOB), problem solving reading strategies (PROB), and support reading strategies (SUP). To interpret the result, the researcher uses this guideline as in (1).

$$
\begin{gathered}
\text { GLOB average }=\frac{\text { GLOB Score }}{13} \\
\text { PROB average }=\frac{\text { PROB Score }}{8} \\
\text { SUP average }=\frac{\text { SUP Score }}{9} \\
\text { ORS average }=\frac{\text { Overall Score }}{30}
\end{gathered}
$$

This strategies used by the students are divided into three categories. It can be global reading strategy, problem solving reading strategy, and support reading strategy. The overall average indicates how often the students use reading strategies when reading academic materials. The average of each subscale shows which group of strategies the students use more often when reading.

\section{CONCLUSION}

This research provides an overall understanding of the use of reading strategies of EFL students English education study by investigating their uses of EFL reading strategies when reading English text. The results revealed that students used EFL reading strategies frequently. Of the three strategy sub-categories, problem-solving reading strategies were used by students the most, followed by support reading strategies and then global strategies. Male students showed greater awareness of EFL reading strategies than female students in all three sub-categories, as well as in the 30 individual reading strategies.

The study findings can help learners especially in Ronggolawe University better understand the current use of EFL reading strategies among them and actions they can take to help them improve their reading abilities. The results of this research may help learners determine the appropriate reading strategies to incorporate into English reading comprehension instruction. However, to ensure success in English reading comprehension, students need to know which strategies to use and how to use them. In addition to using these strategies with high frequency, EFL English department students need to learn to use them effectively.

\section{References}

[1] M. Zoghi, R. Mustapha, N. Rizan, and M. Maasum, "Looking into EFL readingcomprehension." Procedia Social and Behavioral Sciences, vol. 7, pp. 439-445, 2010.
[2] R.E. Slavin and A. Cheung, "A Synthesis of research on language of reading instruction for English language learners." in Review of Educational Research, vol. 2, 2005, pp. 247-284.

[3] N. Maarof and M. Yaacob, "Meaning-making in the first and second language: reading strategies of Malaysian students." in Procedia Social and Behavioral Sciences, 2011, pp. 211-223.

[4] S. Cogmen, and A.S. Saracaloglu, "Students' usage of reading strategies in the faculty of education. " in Procedia Social and Behavioral Sciences, vol. 1, 2009, pp. 248-251.

[5] K. Mokhtari and R. Sheorey, “ Measuring ESL students' awareness of reading strategies." in Journal of Developmental Education,2002, pp. $2-10$.

[6] D.D. Mc Namara and T. O'Reilly, Theories of comprehension skill: language and strategies versus capacity and suppression. Houppauge, NY: Nova Science. 2007.

[7] K. Mokhtari and C. Reichard, "Assessing students' metacognitive awareness of reading strategies." in Journal of Educational Psychology, vol. 2, 2002, pp. 249-259. 